\title{
Clinical strategies for esthetic excellence in anterior tooth restorations: understanding color and composite resin selection
}

\author{
Flavia Pardo Salata NAHSAN 1 , Rafael Francisco Lia MONDELLI ${ }^{2}$, Eduardo Batista FRANCO ${ }^{3}$, Fabiana Scarparo \\ NAUFEL ${ }^{4}$, Julio Katuhide UEDA ${ }^{5}$, Vera Lucia SCHMITT ${ }^{5}$, Wagner BASEGGIO ${ }^{6}$
}

\footnotetext{
1- PhD student, Department of Operative Dentistry, Endodontics and Dental Materials, Bauru School of Dentistry, University of São Paulo, Bauru, SP, Brazil. 2- PhD, Associate Professor, Department of Operative Dentistry, Endodontics and Dental Materials, Bauru School of Dentistry, University of São Paulo, Bauru, SP, Brazil.

3-PhD, Full Professor, Department of Operative Dentistry, Endodontics and Dental Materials, Bauru School of Dentistry, University of São Paulo, Bauru, SP, Brazil.

4- Associate Professor, Department of Operative Dentistry, State University of West Paraná, Cascavel, PR, Brazil.

5- Adjunct Professor, Department of Operative Dentistry, State University of West Paraná, Cascavel, PR, Brazil.

6- Assistant Professor, Department of Operative Dentistry, Paraná University, Cascavel, PR, Brazil.
}

Corresponding address: Flavia Pardo Salata Nahsan - Faculdade de Odontologia de Bauru - USP - Departamento de Dentística, Endodontia e Materiais Dentários - Disciplina de Dentística - Alameda Octávio Pinheiro Brisolla, 9-75 - 17012-901 - Bauru, SP - Brasil - Phone: +55-14-3235-8323 - Fax: +55-143235-5323 - e-mail: flavia_odonto@hotmail.com

Received: March 23, 2010 - Modification: April 30, 2010 - Accepted: October 26, 2010

\section{ABSTRACT}

\begin{abstract}
D irect composite resin restorations have become a viable alternative for patients that require anterior restorative procedures to be integrated to the other teeth that compose the smile, especially for presenting satisfactory esthetic results and minimum wear of the dental structure. Technological evolution along with a better understanding of the behavior of dental tissues to light incidence has allowed the development of new composite resins with better mechanical and optical properties, making possible a more artistic approach for anterior restorations. The combination of the increasing demand of patients for esthetics and the capacity to preserve the dental structure resulted in the development of different incremental techniques for restoring fractured anterior teeth in a natural way. In order to achieve esthetic excellence, dentists should understand and apply artistic and scientific principles when choosing color of restorative materials, as well as during the insertion of the composite resin. The discussion of these strategies will be divided into two papers. In this paper, the criteria for color and material selection to obtain a natural reproduction of the lost dental structures and an imperceptible restoration will be addressed.
\end{abstract}

Keywords: Composite resins. Dental esthetics. Color.

\section{INTRODUCTION}

Technological improvements have taken place in response to the growing demand of the patients for esthetics and the consequent demand of clinicians for materials with similar optical characteristics to those of the natural teeth. Recent composite resins display a wide variety of color and effects, which facilitates different combinations of translucence and opacity. Moreover, they are easier to handle and insert, and facilitate the sculpture of the dental anatomy. Facing these improvements, interventions with composite resins have made possible the reestablishment of specific and individual details existing in the natural dentition, in a satisfactorily esthetic way and practically imperceptible to human vision ${ }^{1,6,7,12}$.

Function, form and esthetic are adequately restored in direct procedures with composite resins, with the restorative conception in close relation to conservative operative interventions.

The improvement of restorative techniques allied to a better understanding of the inherent characteristics of the dental tissues to light incidence allow a more artistic restorative approach where the light can be manipulated in each increment of resin, thus resulting in vivid and extremely natural restorations ${ }^{3,8}$. This paper presents a simple 
and effective technique for color selection and reproduction of the anatomic form of a fractured anterior tooth, discussing the necessary clinical strategies to obtain imperceptible final restorations.

\section{Tooth color selection}

The natural tooth is polychromatic, that is, it has a great variety of colors and nuances that are perceived and interpreted by the human brain ${ }^{16,17}$ (Figures 1 and 2). To artificially reproduce all the intrinsic characteristics of the tooth is not always a simple task. The dentist should have an artistic sense in order to indentify details and define the different nuances of each tooth. Certainly, this clinical step represents much more than a simple selection of a letter $\mathrm{A}$ or $\mathrm{B}$, and a number 1 or 2 , and it influences directly and significantly on the final esthetic outcome ${ }^{17}$.

Color should be understood as the result of the interaction of three dimensions known as hue, chroma and value ${ }^{10,17}$. Hue is defined as the main name of the color perceived by the observer, such as green, red, yellow or blue. In Dentistry, hues are represented by the letters on the resin tubes $(A, B$, $C$ and $D)$. Chroma is understood as the saturation degree or the intensity of the hue, such as light blue, dark blue, royal blue, and is represented in Dentistry by numbers, whose order is crescent in saturation. Value represents the dynamic dimension of the bodies and corresponds to the luminosity of the color, and is related to the amount of the existing white or black pigments ${ }^{8,16}$.

Natural dentin and enamel have a rich composition and details. Whereas dentin confers the basic color to the dental element, or the hue, this color is not entirely perceived by the observer, as the enamel modulates the chroma and the value of the hue according to its greater or smaller thickness. Regions where the thickness of the enamel is smaller, such as the cervical third, tend to be darker when compared to the middle and incisal thirds, as the color conferred by the dentin is less subject to enamel modulation, and thus it is more easily perceived. This area should be the chosen for hue selection. With the increase in enamel thickness towards the middle third, there is a progressive decrease of the intensity or the color chrome. The hue remains the same, although the greater thickness of the enamel interferes in its perception, giving it a less saturated aspect. Therefore, the hue of the tooth is given by the dentin and influenced by the enamel. The enamel does not change the hue, but only confers a greater or lesser saturation or chroma according to its thickness ${ }^{6,8}$.

The value, however, can and should be manipulated by the placement of correct thicknesses of certain resins proper for the reproduction of dentin and enamel, inserted in the respective places to replace lost tissues, or by specific resins that increase or decrease the value, giving the restoration its vivacity.

Color selection should be done on clean teeth and with the natural humidity of the oral cavity. That is necessary because water plays a fundamental role in the final color outcome. Enamel dehydration reduces its translucency by $82 \%$, misleading the clinician to select a lighter and more opaque resin than the natural tooth color. The influence of water in enamel translucence is the result of the exchange of water by air around the enamel prisms. As the rate of refraction of light in water (1.33) and in air (1.0) is different, drying the enamel causes the air to surround the interprismatic spaces and to perceive a lighter and more opaque tooth ${ }^{4}$.

A common mistake in color selection step is to use ceramic shade guides. These are not indicated because their use is specific for prosthetic pieces and they are fabricated from materials that differ completely from composite resins. In addition, it is difficult that the color selected in the ceramic shade guide present any similarity to the corresponding resin color that will be used in the restoration

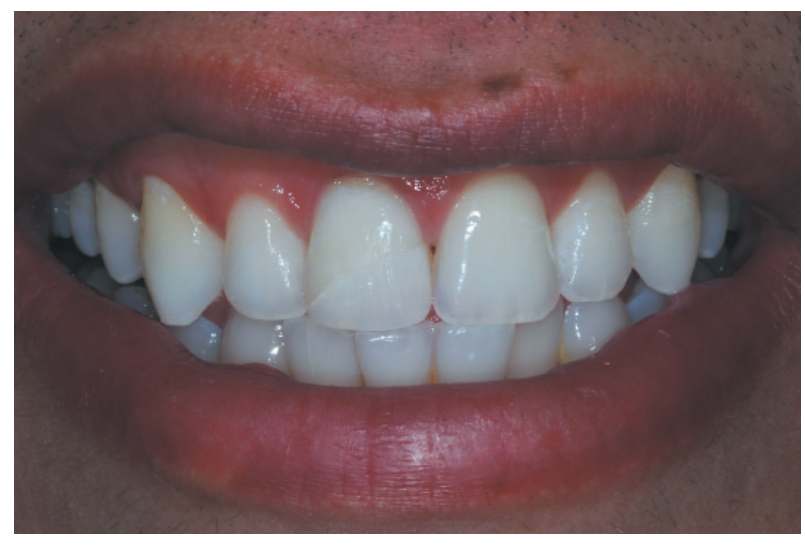

Figure 1- Initial case, showing inadequate reproduction of the polychromatic aspects of tooth

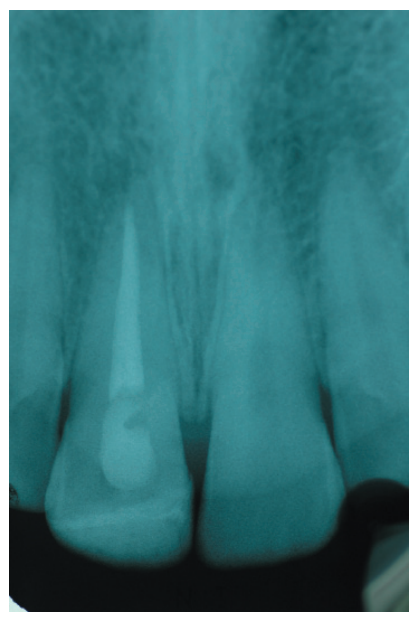

Figure 2- Initial radiograph, showing satisfactory endodontic treatment 
because different commercial brands exhibit different shades for the same hue and chroma, and thus might be more or less similar to the color presented by the natural tooth and the ceramic guide. However, the ceramic shade guide has its relevance in clinical use especially during the initial direction of the predominant tooth color, guiding the dentist to a posterior comparison with the resin that will be used in the procedure.

A custom-made shade guide with different material thicknesses and separation for enamel and dentin is a viable option due to of the possibility of superposition of different thicknesses of enamel and dentin resins in order to obtain the final color outcome (Figure 3).

Another possibility is the positioning and polymerization of small increments of the selected composites over the remaining tooth structure, which is our recommendation.

\section{Composite resin selection}

The percentage of light transmission on the enamel is approximately $70.1 \%$, which gives translucent characteristics to this tissue. On the other hand, the percentage on the dentin is $52.6 \%$, which makes it more opaque ${ }^{13}$. In order to obtain natural characteristics, more transparent resins should be used in the fabrication of artificial enamel, whereas more opaque resins should be used to reproduce artificial dentin. Manufacturers divide their restoration kits in resins specific for enamel (E-enamel, T-translucent) and for dentin (D-dentin, B-body, O-opaque) and also provide resins with specific colors that allow characterization of special effects such as incisal transparency, opalescent halo, hypocalcified and fluoride stains as well as the manipulation of the value in the restoration.

More important than having several commercial brands or kits, is understanding the optical behavior of dental structures in order to select the appropriated resin, thus rationalizing the purchase of materials. In several occasions, resins of different brands are selected to create a personal kit, appropriate for the peculiar characteristics of the tooth the dentist wishes to reproduce, because some effects are better reproduced by certain types of resin. Thus, the clinician may use an $A 2$ resin of a commercial brand, the opalescent and translucent effect of another one, and a third that can best mimic the value of the tooth in the same restoration.

The insertion of different types of resin as well as the colors must be done by a technique that allows the restoration of enamel and dentin separately $2,6,7,10,11,14$. This incremental approach allows the perfect masking limits between tooth and restoration reproducing more accurately the optical and physical-mechanical characteristics of each dental substrate ${ }^{2}$. The need of any additional wear of the dental structure, excluding the removal of carious tissue and/or defective restoration, is discarded, especially in children and adolescents, for preserving the sound structure. At each restoration replacement there is an inevitable removal of healthy dental structure. The younger the patient, the larger the number of replacements he/she will need throughout his/her life, with detrimental effects to biology, function and esthetic of the teeth. Therefore, the initial composite resin restoration should be as conservative as possible, preserving the dental structure and reducing costs and complexity of eventual future replacements.

\section{Artificial reproduction of enamel}

Reproduction of enamel should be done with a resin that presents transparent characteristics. Frequently, the color used for enamel corresponds to the one used for external dentin. However, this is not a rule as there might be variations in chrome due to thickness and individual characteristics of the enamel. Young teeth show a naturally high value and thus require resins with such characteristics.

\section{Reproduction of palatal enamel}

The palatal enamel can be constructed with the use of a polyester matrix, pre-fabricated acetate crowns, or custom-made guides (Figures 4 and 5 ). This last option has advantages in restorative procedures by providing harmonic cervico-incisal and mesiodistal dimensions previously visualized in the wax pattern; appropriate control of the thickness of the resin increment; better visualization of the final dimensions of the tooth (width and length) in an early stage of the restoration; and enough support to restore the lost palatal enamel ${ }^{8}$.

After administration anesthesia, the restoration was removed and a rubber dam was used. The $37 \%$ phosphoric acid was applied to the enamel for $15 \mathrm{~s}$ and then to the dentin for $15 \mathrm{~s}$ (total acid application to enamel was $30 \mathrm{~s}$ ). The tooth was rinsed for 30 $\mathrm{s}$ and slightly dried with absorbent paper to keep the dentin moist for adhesive system application. Next, after $20 \mathrm{~s}$ polymerization of the adhesive, the first layer of a microhybrid composite resin for enamel was inserted. A translucent composite resin was applied to obtain similarly to that of natural enamel. This portion was inserted in order to fill the entire palatal region of the polyester matrix previously developed, favoring the reproduction of the anatomic configuration.

\section{Artificial reproduction of dentin}

Dentin reproduction should be done with a resin that presents opaque characteristics ${ }^{15}$. After selecting the hue on the cervical area, as well as its saturation degree, the clinician should now divide dentin construction in two parts. 


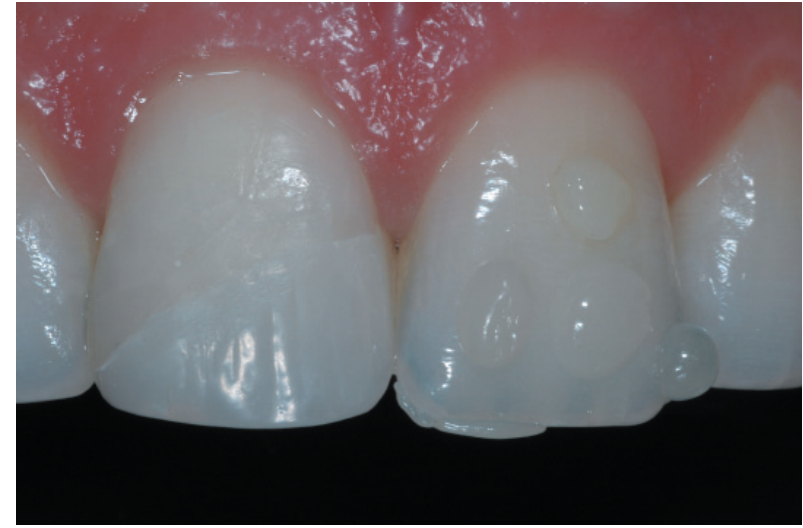

Figure 3- Shade selection performed on a clean tooth under the natural humidity, with a large combination of composite resins attempting to identify the fine shade differences at each tooth region

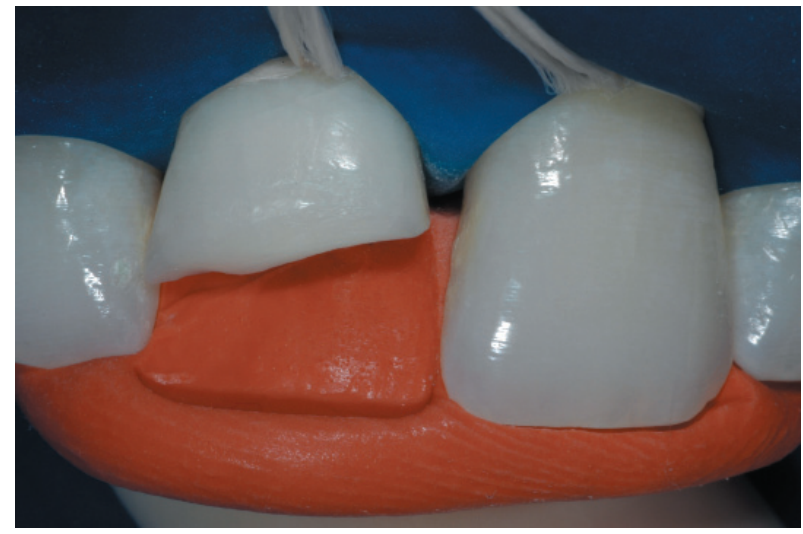

Figure 4- Artificial palatal enamel made using a silicon personalized guide

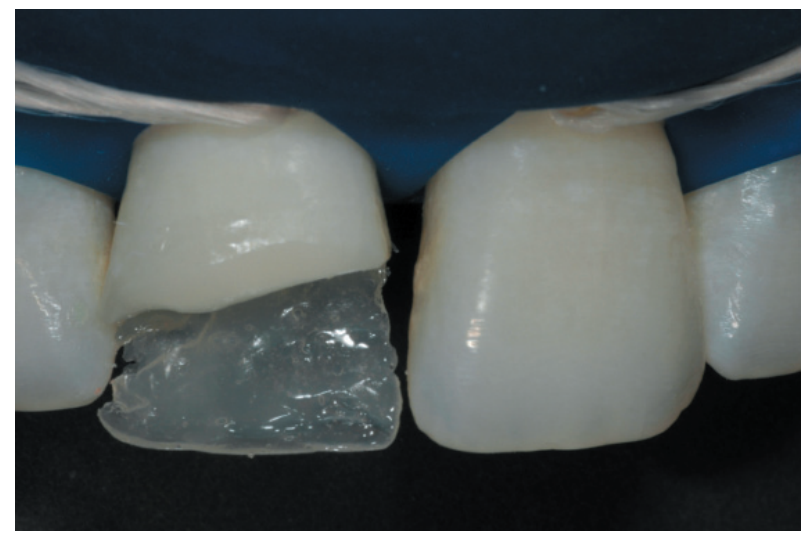

Figure 5- Application of translucent resin to reproduce the palatal portion of the tooth. Note the translucency achieved by Amaris ${ }^{\circledR} \mathrm{TL}$, ideal to reproduce the enamel that was lost

\section{Internal artificial dentin}

In natural teeth, there is a progressive decrease in chrome from the cervical to the incisal area, as well as from the most internal towards the surface of the tooth ${ }^{17}$. These differences should be reproduced

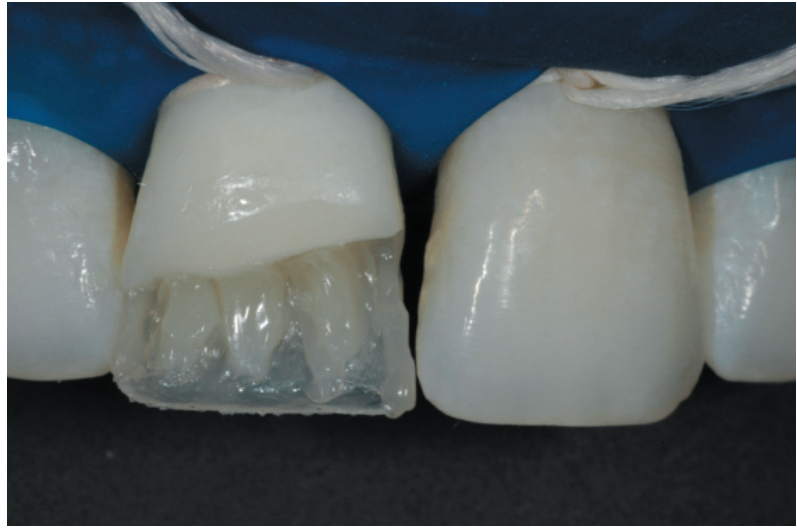

Figure 6- Reproduction of the deepest artificial dentin with more opaque characteristics

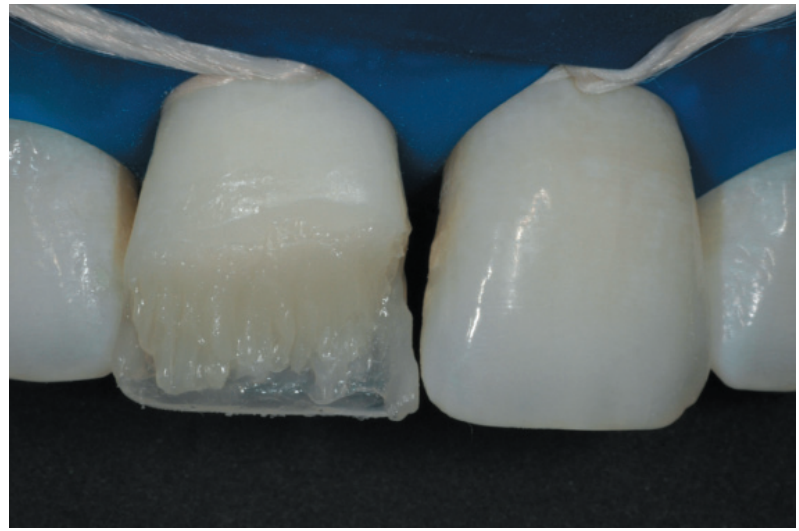

Figure 7-Application of Amaris ${ }^{\circledR} \mathrm{O} 1$ to reproduce a more superficial dentin

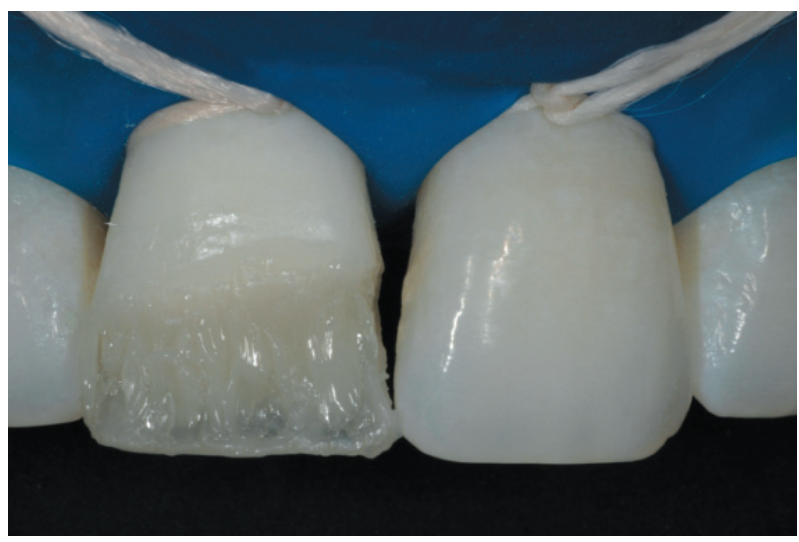

Figure 8-Application of Amaris ${ }^{\circledR} \mathrm{TL}+$ high opaque to mimic the effect of opalescent halo. Amaris ${ }^{\circledR} \mathrm{HT}$ was inserted to reproduce the incisal translucency

in order to achieve the harmonious and natural aspect of the restoration. When reproducing the artificial dentin localized in the inner part of the restoration and directed to the cervical third, the chrome should be increased in one number (Figure 6 ). This resin must present a high-chrome shade in order to simulate the optical properties of the tooth. 


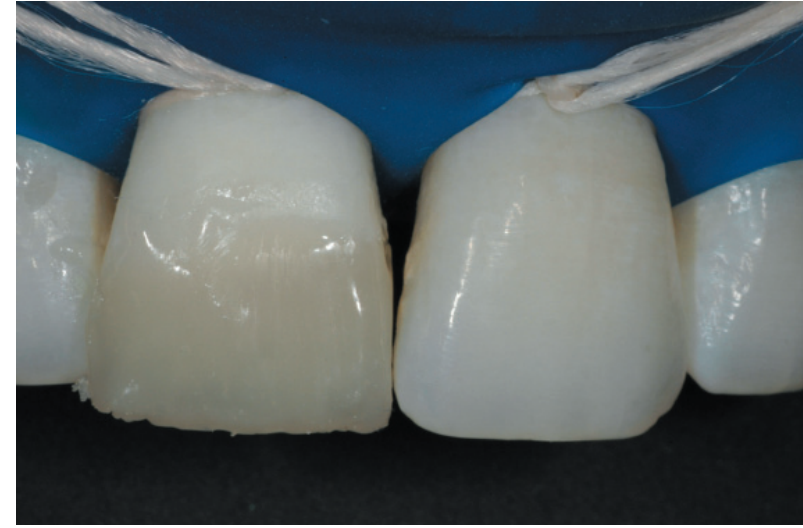

Figure 9- Application of Amaris ${ }^{\circledR}$ TN over the other shades, reproducing the buccal enamel

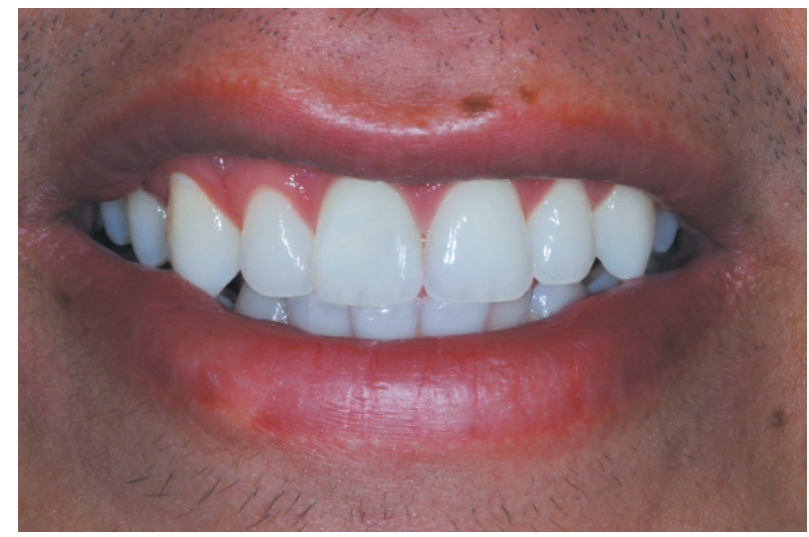

Figure 10- Final esthetic outcome

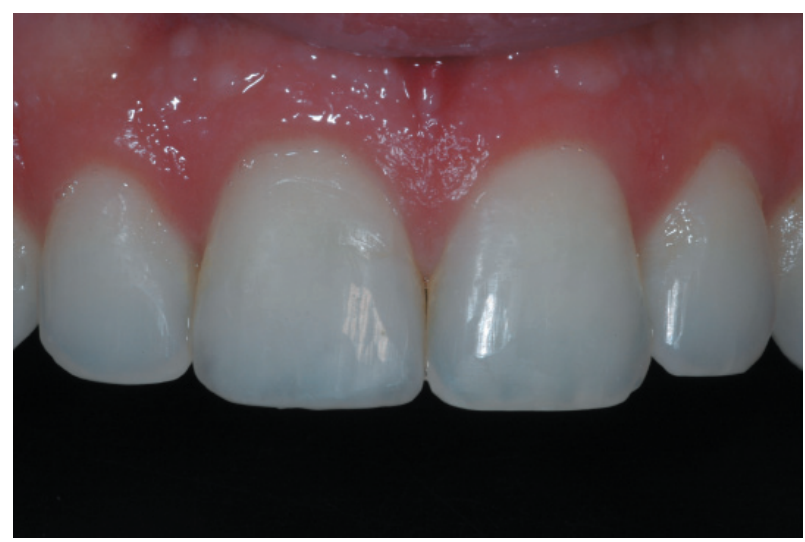

Figure 11- Follow-up at 12 months

\section{External artificial dentin}

When reproducing external artificial dentin, that is the dentin found closer to enamel-dentin junction, as well as the dentin found in middle third and directed to incisal third. Using resins with fluorescent optical properties is very favorable in this step. In this phenomenon some substances when submitted to ultraviolet radiations emit visible light. The atoms of these fluorescent substances absorb ultraviolet radiation, invisible to human eyes, and emit visible light. The name of this phenomenon comes from fluorite, which is the best example of a fluorescent mineral.

In this step the resin should be slightly directed towards the cavosurface angle, in order to hide the tooth/restoration limit (Figure 7). To "blend" the restoration into the tooth structure and to disguise the fracture or limit line, the artificial dentin increment was lightly feathered between the lingual enamel layer and the facial enamel. Also, a resin with opaque and translucent characteristics should be used to mimic the effect of opalescent halo and reproduce the incisal translucency, respectively ${ }^{2}$ (Figure 8).

Esthetic areas can be restored with microhybrid resins as they provide tooth-like optical properties to mimic the natural characteristics coordinated with the natural teeth.

\section{Reproduction of buccal enamel}

To reproduce buccal enamel, the resin should be inserted in one single increment in order to minimize the occurrence of union lines on the buccal face of the restoration (Figure 9). This is possible because the thickness of the resin does not surpass $2 \mathrm{~mm}$ and the C-factor of cavity configuration is small in such preparations ${ }^{9}$. This increment should, preferably, be placed from the most cervical to the most incisal region, using appropriate spatulas and brushes. The analysis of the incisal region and the profile of the restoration with mirrors as well as comparison with the contralateral tooth are essential for guiding on the reconstruction of the buccal anatomy. The use of specific paintbrushes to apply this layer is recommended for reproducing the texture of enamel surface and improving the optical characteristics of the restoration.

Finishing and polishing of anatomy and details of morphology were performed at another session (Figure 10). Figure 11 shows the clinical aspect of the composite resin restoration after 12 months of follow-up, with good color stability of the material.

\section{CONCLUSIONS}

The esthetic characteristics of current composite resins and the better understanding of the behavior of dental tissues under light incidence allow the accomplishment of an imperceptible restoration. It is fundamental to have an accurate knowledge about the translucency and colors of the materials used.

\section{ACKNOWLEDGMENTS}

The authors would like to thank VOCO GmbH (Germany) for gently donating the composite resin Amaris ${ }^{\circledR}$ used in this clinical case. The authors do not have any financial interest in the company that 
donated the materials used in this case.

\section{REFERENCES}

1- Araujo EM Jr, Baratieri LN, Monteiro S Jr, Vieira LC, Andrada MA. Direct adhesive restoration of anterior teeth: part 2. Clinical protocol. Pract Proced Aesthet Dent. 2003;15(5):351-7.

2- Baratieri LN, Araujo E, Monteiro S Jr. Color in natural teeth and direct resin composite restorations: essential aspects. Eur J Esthet Dent. 2007;2(2):172-86.

3- Blank JT. Creating translucent edge effects and maverick internal tints using microhybrid resin. Pract Proced Aesthet Dent. 2006;18(2):131-6.

4- Brodbelt RHW, O'Brien WJ, Fan PL. Translucency of dental porcelains. J Dent Res. 1980;59:70-5.

5- Dietschi D. Free-hand composite resin restorations: a key to anterior aesthetics. Pract Periodontics Aesthet Dent. 1995; 7(7):15-25.

6- Dietschi D. Optimising aesthetics and facilitating clinical application of free-hand bonding using the "natural layering concept". Br Dent J. 2008;204(4):181-5.

7- Dietschi D, Ardu S, Krejci I. A new shading concept based on natural tooth color applied to direct composite restorations. Quintessence Int. 2006;37(2):91-102.

8- Franco EB, Francischone CE, Medina-Valdivia, JR, Baseggio W. Reproducing the natural aspects of dental tissues with resin composites in proximoincisal restorations. Quint Int. 2007;38:50510.
9- Lopes LG, Franco EB, Pereira JC, Mondelli RFL. Effect of lightcuring units and activation mode on polymerization shrinkage and shrinkage stress of composite resins. J Appl Oral Sci. 2008;16(1):35-42.

10- Magne P, Holz J. Stratification of composite restorations: systematic and durable replication of natural aesthetics. Pract Periodontics Aesthet Dent. 1996;8(1):61-8.

11- Marus R. Treatment planning and smile design using composite resin. Pract Proced Aesthet Dent. 2006;18(4):235-41.

12- Ozel E, Kazandag MK, Soyman M, Bayirli G. Two-year follow-up of fractured anterior teeth restored with direct composite resin: report of three cases. Dent Traumatol. 2008;24(5):589-92.

13- Peyton JH. Direct restoration of anterior teeth: review of the clinical technique and case presentation. Pract Proced Aesthet Dent. 2002;14(3):203-10.

14- Portalier L. Diagnostic use of composite in anterior aesthetics. Pract Periodontics Aesthet Dent. 1996;8(7):643-52.

15- Terry DA. Color matching with composite resin: a synchronized shade comparision. Pract Proced Aesthet Dent. 2003;15(7):51521.

16- Terry DA. Dimensions of color: creating high-diffusion layers with composite resin. Compend Contin Educ Dent. 2003;24:3-13. 17- Vanini L. Light and color in anterior composite restorations. Pract Periodontics Aesthet Dent. 1996;8(7):673-82. 